\title{
Cellular localization of protein arginine methyltransferase-5 correlates with grade of lung tumors
}

\author{
Konstantin Shilo ${ }^{*}$, Xin $\mathrm{Wu}^{2}$, Smita Sharma ${ }^{3}$, Meng Welliver ${ }^{3}$, Wenrui Duan², Miguel Villalona-Calero², \\ Junya Fukuoka ${ }^{4}$, Said Sif ${ }^{5}$, Robert Baiocchi ${ }^{2}$, Charles L Hitchcock ${ }^{1}$, Weiqiang Zhao ${ }^{1}$ and Gregory A Otterson ${ }^{2}$
}

\begin{abstract}
Background: Protein arginine methyltransferase-5 (PRMT5) is a chromatin-modifying enzyme capable of methylating histone and non-histone proteins, and is involved in a wide range of cellular processes that range from transcriptional regulation to organelle biosynthesis. As such, its overexpression has been linked to tumor suppressor gene silencing, enhanced tumor cell growth and survival.
\end{abstract}

Material and methods: Quantitative real-time polymerase chain reaction, Western immunoblot and immunohistochemistry were used to characterize PRMT5 expression in lung cancer cell lines and human tumors. Clinicopathological findings of tissue microarray based samples from 229 patients with non-small cell lung carcinomas (NSCLC) and 133 cases with pulmonary neuroendocrine tumors (NET) were analyzed with regard to nuclear and cytoplasmic PRMT5 expression.

Results: There was statistically significant difference in PRMT5 messenger RNA expression between tumors and nonneoplastic lung tissues. Immunoblot experiments showed abundant expression of PRMT5 and its symmetric methylation mark H4R3 in lung carcinoma but not in non-neoplastic human pulmonary alveolar and bronchial epithelial cell lines. More than two thirds of lung tumors expressed PRMT5. High levels of cytoplasmic PRMT5 were detected in $20.5 \%$ of NSCLC and in $16.5 \%$ of NET; high levels of nuclear PRMT5 were detected in $38.0 \%$ of NSCLC and $24.0 \%$ of NET. Cytoplasmic PRMT5 was associated with high grade in both NSCLC and pulmonary NET while nuclear PRMT5 was more frequent in carcinoid tumors $(p<0.05)$.

Conclusion: The observed findings support the role of PRMT5 in lung tumorigenesis and reflect its functional dichotomy in cellular compartments.

Virtual slide: The virtual slides for this article can be found here: http://www.diagnosticpathology.diagnomx.eu/ vs/1611895162102528

Keywords: Protein arginine methyltransferase-5, Lung carcinoma, Neuroendocrine tumors

\section{Background}

Lung cancer remains the greatest cause of cancer death, outnumbering the next three causes, colorectal, breast and prostate cancer combined. In 2011, it was estimated that more than 220,000 Americans would be diagnosed with lung cancer, and more than 150,000 people die from this disease [1]. Despite the development of targeted therapies

\footnotetext{
* Correspondence: Konstantin.Shilo@osumc.edu

'Department of Pathology, The Wexner Medical Center at the Ohio State University, 410 W. 10th Avenue, Columbus, OH, 43210, USA

Full list of author information is available at the end of the article
}

directed against "driver" mutations in EGFR and ALK, nearly $50 \%$ of non-small cell lung carcinomas (NSCLC) currently lack identifiable mutations in these sites and therefore more targets beyond DNA mutation analysis including DNA methylation, mRNA and micro RNA expression analysis are a focus of investigations in lung cancer and other malignancies [2-6]. In particular DNA methylation of tumor suppressor genes has been found throughout entire spectrum of NSCLC and to be a nearly universal abnormality in squamous lung cancers $[3,7,8]$.

\section{Biomed Central}

(c) 2013 Shilo et al.; licensee BioMed Central Ltd. This is an open access article distributed under the terms of the Creative Commons Attribution License (http://creativecommons.org/licenses/by/2.0), which permits unrestricted use, distribution, and reproduction in any medium, provided the original work is properly cited. 
DNA methylation of tumor suppressor genes was identified as having equivalent functional consequences as mutation of key tumor suppressor genes [9,10]. In contrast to mutations, DNA methylation is reversible, raising the possibility of "epigenetic" therapy by the use of hypomethylating agents to tumors with DNA hypermethylation. Two cytosine analogues that are incorporated into DNA during S-phase and block the maintenance DNA methylation machinery through the inhibition of DNA methyltransferase enzymes (DNMT) show benefit in myeloid tumors $[11,12]$.

Similar to DNMT, protein arginine methyltransferase 5 (PRMT5) has been shown to be involved in silencing of tumor suppressor genes promoting neoplastic transformation. PRMT5, along with PRMT7 and PRMT9, forms a group of type II PRMT enzymes that catalyze symmetric arginine methylation of histones and non-histone proteins $[13,14]$. PRMT5 symmetrically methylates $\mathrm{N}$-terminal of histones H3 (at Arginine position 8, S(Me2) H3R8), and H4 (at Arginine $3 \mathrm{~S}(\mathrm{Me} 2) \mathrm{H} 4 \mathrm{R} 3$ ), and leads to transcriptional silencing of regulatory and tumor suppressor genes [15]. Knockdown of PRMT5 leads to slower cellular growth, while over-expression of PRMT5 leads to cellular hyperproliferation. The overexpression of PRMT5 has been found in hematological and epithelial malignancies including lymphoma, prostate and lung cancer cell lines [14,16-18]. The cellular functions of PRMT5 are diverse and are, in part, related to nuclear or cytoplasmic localization (reviewed in [19]). In the nucleus, it is associated with several protein complexes including SWI/SNF chromatin remodelers. In the cytoplasm, PRMT5 forms a
20S protein arginine methyltransferase complex, termed the "methylosome," consisting of spliceosomal snRNP Sm proteins, PRMT5, pICln, and WD repeat protein (MEP50/ WD45) [20-22].

Since only limited data is available regarding the role PRMT5 in lung cancer, the goal of this study was to evaluate a large set of NSCLC and pulmonary neuroendocrine tumors (NET) for PRMT5 expression and the potential correlation of expression with clinicopathological variables.

\section{Material and methods}

\section{Cell lines, resection specimens and tissue microarrays}

NSCLC cell lines (NCI-H1299, NCI-A549, NCI-H520) and small cell lung carcinoma cell lines (NCI-H69 and NCI-H719) were obtained from American Type Culture Collection (Manassas, VA), Table 1. Non-malignant cell lines of human pulmonary alveolar epithelial cells (HPAEpiC) and human bronchial epithelial cells (HBEpiC) were obtained from ScienCell Research Laboratories (Carlsbad, CA). The cells were grown in routine media without cell cycle synchronization. The cell cultures were propagated for 7-14 days then collected and centrifuged and cell suspension pellets were either used for western immunoblotting or for immunohistochemistry (IHC) following paraffin embedding.

Six frozen tissue samples of adenocarcinoma (ADC) and 2 of squamous cell carcinoma (SQC) with matched nonneoplastic lung parenchyma (8 samples) were used

Table 1 Overview of employed materials

\begin{tabular}{|c|c|c|c|}
\hline Material & & Features (n) & Source \\
\hline \multirow[t]{7}{*}{ Cell line } & $\mathrm{NCl}-\mathrm{H} 1299$ & Non-small cell lung carcinoma & American type culture collection (Manassas, VA \\
\hline & NCl-A549 & Adenocarcinoma & \\
\hline & $\mathrm{NCl}-\mathrm{H} 520$ & Squamous cell carcinoma & \\
\hline & $\mathrm{NCl}-\mathrm{H} 69$ & Small cell lung carcinoma & \\
\hline & $\mathrm{NCl}-\mathrm{H} 719$ & Small cell lung carcinoma & \\
\hline & HPAEPiC & Human pulmonary alveolar epithelial cells & Sciencell research laboratories (Carlsbad, CA) \\
\hline & HBEpiC & Human bronchial epithelial cells & \\
\hline \multirow[t]{2}{*}{ Frozen tissue } & & Adenocarcinoma (6) & $\begin{array}{l}\text { Surgically resected tumors } \\
\text { (Ohio State University Medical Center) }\end{array}$ \\
\hline & & Squamous cell carcinoma (2) & \\
\hline \multirow[t]{4}{*}{ Paraffin embedded tissue } & & Adenocarcinoma (3) & $\begin{array}{l}\text { Surgically resected tumors } \\
\text { (Ohio State University Medical Center) }\end{array}$ \\
\hline & & Squamous cell carcinoma (3) & \\
\hline & & Large cell neuroendocrine carcinoma & \\
\hline & & Small cell lung carcinoma (2) & \\
\hline \multirow[t]{2}{*}{ Tissue microarray } & & $0.6 \mathrm{~mm}$ cores of non-small cell lung carcinoma (300) & Previously constructed $[23,24]$ \\
\hline & & $\begin{array}{l}0.6 \mathrm{~mm} \text { cores in duplicates of } \\
\text { pulmonary neuroendocrine tumors (183) }\end{array}$ & \\
\hline
\end{tabular}


for mRNA analysis. Three paraffin embedded samples of surgically resected lung ADC, 3 samples of SQC, 2 samples of small cell lung carcinoma (SCLC) and 1 large cell neuroendocrine carcinoma (LCNEC) were utilized for initial immunohistochemical analysis. The human tissues were collected in accordance with the institutional review board approved protocol.

Possible correlations between PRMT5 expression and clinicopathological variables were analyzed utilizing tissue microarrays (TMA) representing NSCLC and pulmonary NET previously constructed from the archival material of Armed Forces Institute of Pathology [23,24]. In short, the TMA comprised $0.6 \mathrm{~mm}$ cores obtained in duplicates from formalin-fixed paraffin-embedded tissue of 183 surgically resected pulmonary NET and $0.6 \mathrm{~mm}$ cores obtained from formalin-fixed paraffin-embedded tissue of 300 surgically resected NSCLC dating to the period from January 1980 to 2004. Eighty three tissue cores of non-neoplastic pulmonary parenchyma from the same cohorts served as normal control. After adjusting for core dropout, NSCLC TMA comprised clinical pathological annotations for 229 cases including 113 (49.3\%) patients with ADC and 116 (50.7\%) with SQC. Their median age was 65 years (range, from 36-86) including 24.4\% females and $75.6 \%$ males. Staging information was available in 141 (61.6\%) cases. Follow-up information was available in 189 (82.5\%) cases with mean follow-up of 3.4 years (range from 0.1-14.2). NET TMA comprised annotations for 133 patients including 40 (30.1\%) with typical carcinoid (TC) tumors, $23(17.3 \%)$ with atypical carcinoid (AC) tumors, 19 (14.3\%) with LCNEC, and 51 (38.4\%) with SCLC. Their median age was 62 years (range, from 19-82) including $48.1 \%$ females and $51.9 \%$ males. Staging information was available in 100 (75.2\%) cases. Follow-up information was available in 100 (75.2\%) cases with mean follow-up of 4.3 years (range from $0.1-24.1$ ). There were 83 samples of normal lung parenchyma included from the same patient population.

\section{Western immunoblot}

Western immunoblot analysis was carried out according to standard protocol. Briefly, $30 \mu \mathrm{g}$ of the total protein isolated from cells were used. Protein concentration was measured using a bicinchoninic acid protein assay kit (Pierce, Thermo Fisher Scientific, Rockford, IL). The primary antibody against PRMT5 $(0.8 \mathrm{mg} / \mathrm{ml})$ and Histone $\mathrm{H} 4$ (symmetric di methyl R3, $0.9 \mathrm{mg} / \mathrm{ml}$ ) were obtained from Abcam (Cambridge, MA) and anti- $\beta$-actin from Santa Cruz Biotechnology (Santa Cruz, CA). The secondary antibody was horseradish peroxidase-conjugated goat anti-rabbit or mouse IgG. Proteins were detected using enhanced chemiluminescence and films (GE Healthcare).

\section{Real time polymerase chain reaction}

Total RNA was isolated from frozen tissue using Trizol RNA isolation following the protocol supplied by the manufacturer (GIBCO BRL, Rockville, MD). RNA samples were treated with DNase (Ambion Inc, Austin, TX) to remove contaminating DNA and stored in $-70^{\circ} \mathrm{C}$ freezer. Quantitation of mRNA expression was carried out using TaqMan real time polymerase chain reaction (PCR). Primers and probe used for the real time PCR analysis were obtained from Applied Biosystems (Foster City, CA). Reverse transcription was performed utilizing SuperScript II Reverse Transcriptase Kit (Applied Biosystems, Foster City, CA). Briefly, 500 ng of template total RNA was reverse transcribed in a $15 \mu \mathrm{l}$ reaction. The PCR amplification was conducted in $25 \mu \mathrm{l}$ reaction using the TaqMan Universal PCR Master Mixture (Applied Biosystems, Foster City, CA) according to the protocol supplied by the manufacturer. Real-time PCR was carried out in a 96-well plate using an Applied Biosystems 7900HT Sequence Detection System at $95^{\circ} \mathrm{C}$ for 10 minutes, followed by 40 cycles of $95^{\circ} \mathrm{C}$ for 15 seconds and $60^{\circ} \mathrm{C}$ for 1 minute. Each sample was evaluated in triplicate and each reaction was repeated at least once to ensure reproducibility. The PCR cycle number at threshold (CT) was used for the comparison. The relative quantitative method was used for the quantitative analysis. Calibrator was the averaged $\Delta \mathrm{Ct}$ from the non-tumor tissues. Endogenous control was ribosome RNA 18 gene (Applied Biosystems, Foster City, CA).

\section{Immunohistochemical analysis}

IHC staining was performed in standard fashion on paraffin-embedded tissue. Paraffin embedded cell line pellet, resection and TMA block were cut at 4-microns and sections were placed on positively charged slides. Slides with sections were then placed in a $60^{\circ} \mathrm{C}$ oven for 1 hour, cooled, deparaffinized and rehydrated through xylenes and graded ethanol solutions to water. All slides were quenched for 5 minutes in a 3\% hydrogen peroxide solution in water to block endogenous peroxidase. Slides then underwent heat-induced epitope retrieval employing Target Retrieval Solution (S1699, Dako, Carpinteria, CA) for 25 minutes at $96^{\circ} \mathrm{C}$ in a vegetable steamer (Black \& Decker) and cooled for 15 minutes. Slides were then placed on a Dako Autostainer Immunostaining System. All incubations on the Autostainer were at room temperature. The primary rabbit polyclonal anti PRMT5 antibody (Abcam, Cambridge, MA) at 1:70 dilutions for tissues and at 1:150 for cell lines was incubated for 60 minutes. The two components of Mach 4 Universal Alkaline Phosphatase Polymer Kit (M4U536L, Biocare Medicals, Concord, CA) were applied sequentially for 15 minutes each. Staining was visualized with the Vulcan Fast Red chromogen (FR8055; 15 minutes development, Biocare Medicals, Concord, CA). Slides were then counterstained in Richard 

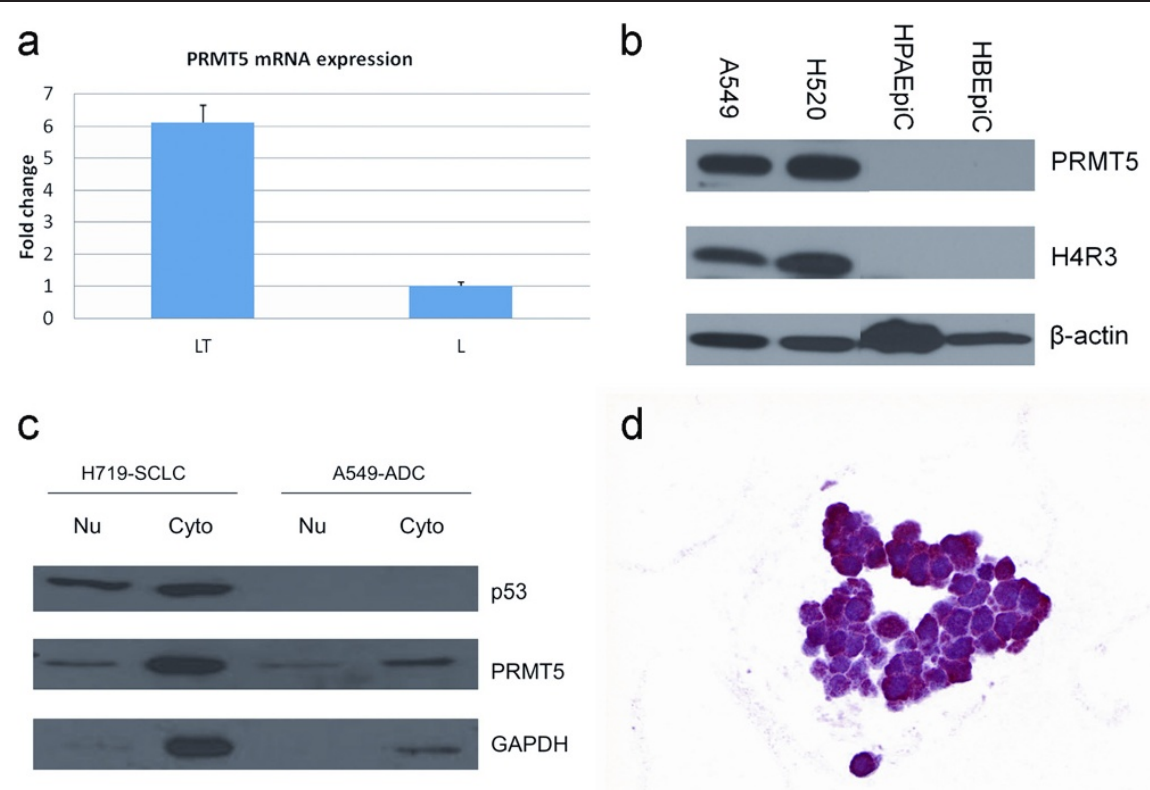

Figure 1 PRMT5 overexpression in lung cancer is evident at mRNA and protein levels. (a) There is a 6.13-fold increase in PRMT5 mRNA levels in lung tumors (LT), 8 cases, over matched nonneoplastic pulmonary parenchyma (L), as evident by TaqMan real time polymerase chain reaction (PCR). (b) PRMT5 and its symmetric methylation mark H4R3 are detected in lung carcinoma cell lines (NCl-A549, NCl-H520) but not in the nonneoplastic human pulmonary alveolar (HPAEpiC) and bronchial epithelial cell lines (HBEpiC); cellular localization experiments highlight nuclear and cytoplasmic fractions of PRMT5; Western immunoblot (b, c); immunohistochemistry (d), NCl-H69, original magnification ×600.

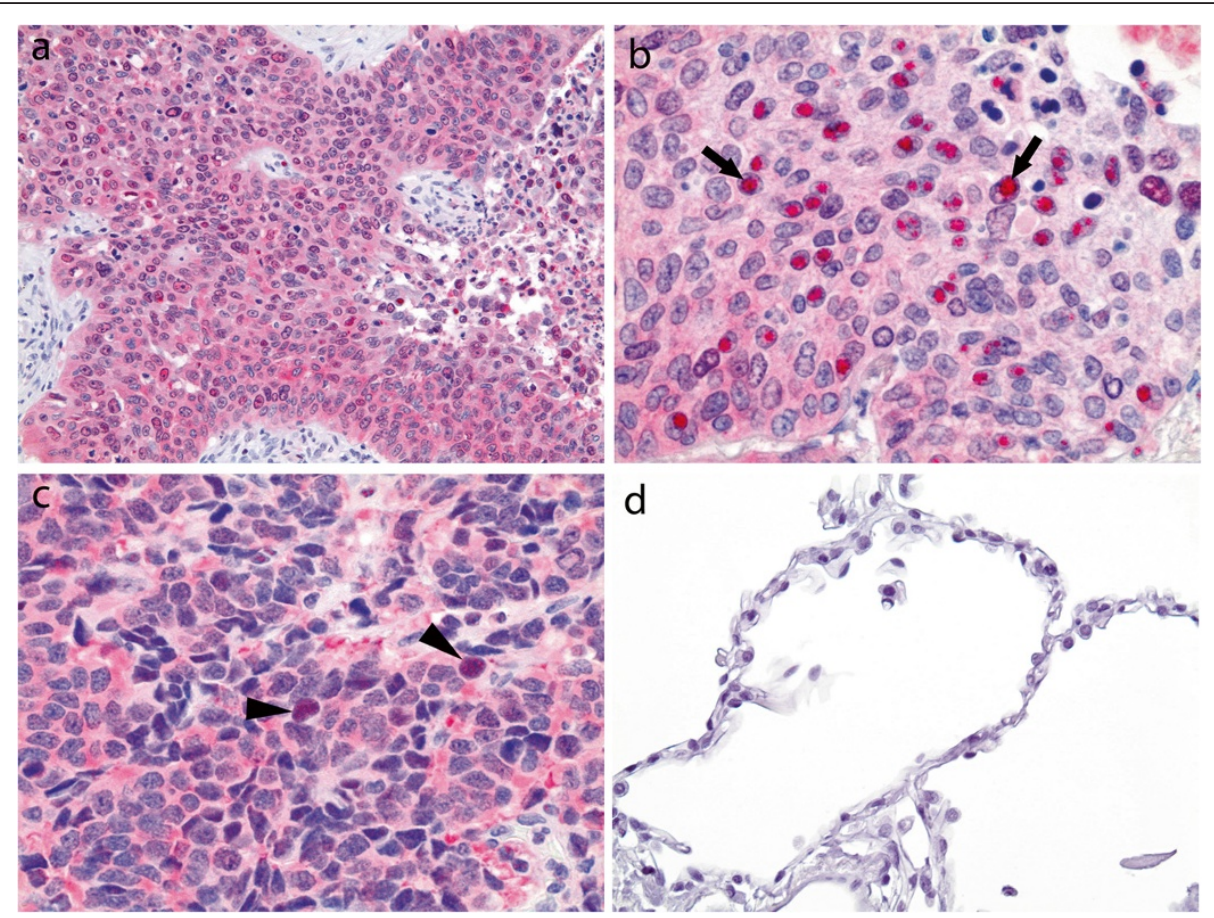

Figure 2 Patterns of PRMT5 expression in surgically resected lung tumors. Cytoplasmic PRMT5 is seen diffusely throughout a tumor (a-c) while nuclear expression varies (b-c); squamous cell carcinoma (a-b); small cell lung carcinoma (c); immunohistochemistry, original magnification $\times 200, \times 600$, and $\times 600$, respectively. A distinct nuclear accumulation of PRMT5 forming varying in size intranuclear globules is seen in squamous cell carcinoma, arrows (b); in contrast, nuclear accumulation of PRMT5 in small cell lung carcinoma is finely granular, arrowheads (c). No PRMT5 expression is seen in alveolar parenchyma away from tumors (d), immunohistochemistry, original magnification $\times 400$. 
Allen hematoxylin (Thermo Scientific, Middletown, VA), dehydrated through graded ethanol solutions, cleared in xylene and coverslipped.

Based on the expression patterns identified in the resection specimens, the tumor cell staining in TMA was evaluated in comparison to normal alveolar parenchyma. Since cytoplasmic expression was evenly distributed within a tumor but varied in intensity, the cytoplasmic expression was assessed as negative (lack of staining), low (weak staining) and high (strong staining). Since number of PRMT5 expressing nuclei varied within a tumor, the nuclear expression was assessed as negative (lack of staining), low (staining in less than $50 \%$ of nuclei) and high (staining in $50-100 \%$ of nuclei).

\section{Statistical analysis}

The mRNA expression levels were summarized graphically by plotting the mean and standard deviation of PRMT5 based on multiple amplifications. A $t$ test was performed to compare the expression values in tumor samples with the values obtained from matched nontumor samples. The associations between clinicopathologic variables and PRMT5 protein expression were examined with Pearson Chi-Square test. Survival probabilities were calculated using the Kaplan-Meier method and compared with the log-rank test. Prognostic significance of PRMT5 expression was evaluated with Cox regression model. Results with a p-value less than 0.05 were considered statistically significant. Data analysis was performed
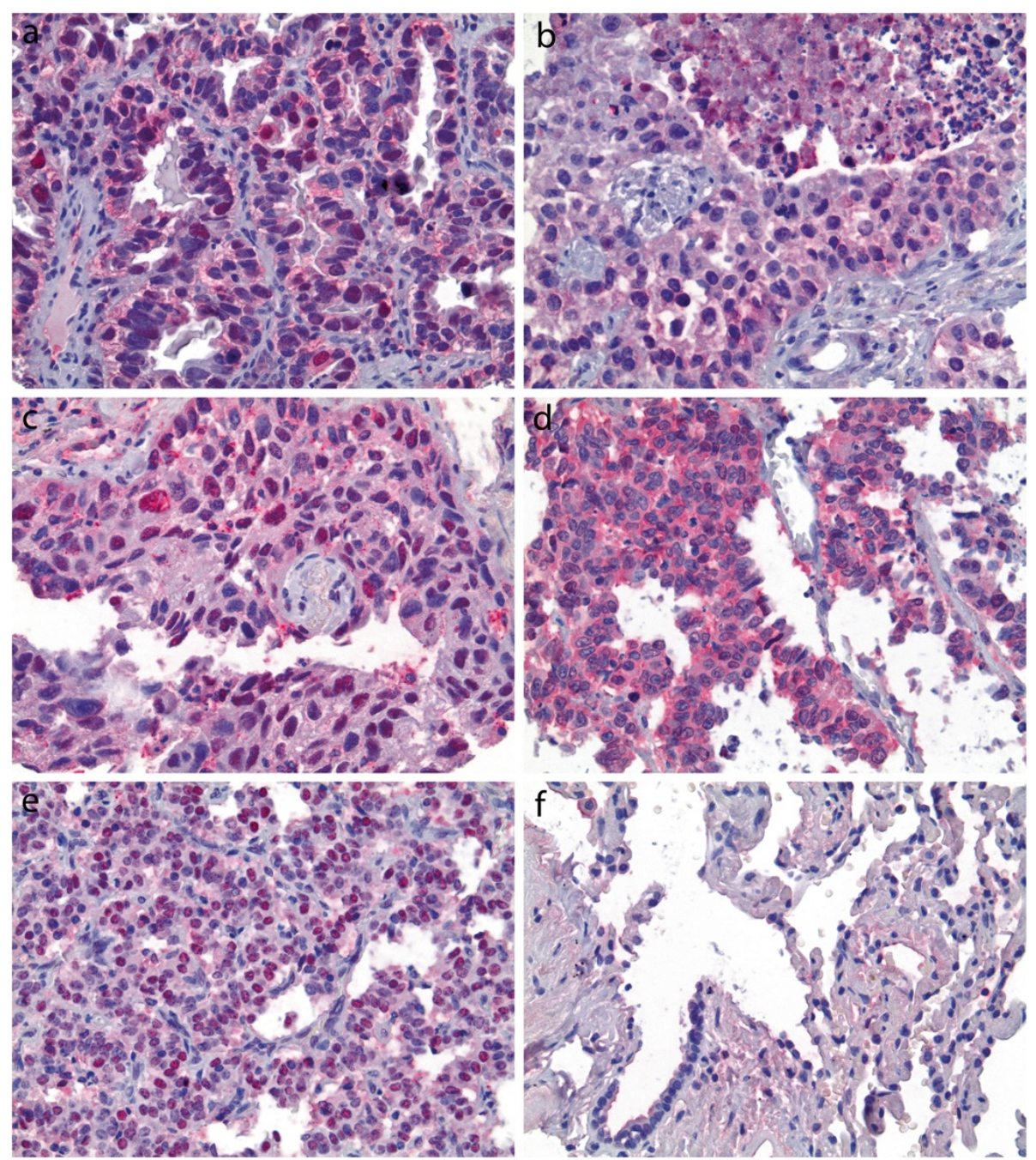

Figure 3 Cytoplasmic (a-e) and nuclear ( $a, c$ and e) expression of PRMT5 is seen throughout the entire spectrum of lung tumors; representative examples of adenocarcinoma (a), squamous cell carcinoma (b-c), large cell neuroendocrine carcinoma (d) and typical carcinoid tumor (e); no PRMT5 is observed in normal alveolar parenchyma (f) Panels (b) and (d) illustrate low and high cytoplasmic expression, respectively; panels (a) and (e) illustrate low and high nuclear expression, respectively; immunohistochemistry; original magnification $\times 400$. 
utilizing statistical package SYSTAT 13.0 (Systat Software Inc., Chicago, IL).

\section{Results}

PRMT5 is differentially expressed in malignant and normal lung tissue

Mean PRMT5 mRNA evaluated with Taqman real time PCR was 6.13 fold higher in NSCLC samples than that in matched non-neoplastic pulmonary parenchyma, $\mathrm{p}=0.030$ (Figure 1a). Western immunoblot showed abundant expression of PRMT5 and its symmetric methylation mark S(Me2)H4R3 in lung ADC (NCI-A549) and SQC (NCI-H520) cell lines, but not in human pulmonary alveolar and bronchial epithelial cells (Figure 1b). Following protein fractionation, distinct bands of PRMT5 were seen in both cytoplasm and nucleus (Figure 1c). Cytoplasmic and nuclear expression of PRMT5 was identified in 5 of 5 lung carcinoma cell lines, including NSCLC (NCI-H1299), ADC (NCI-A549), SQC (NCI-H520), and SCLC (NCI-H69 and NCI-H719, Figure 1d). PRMT5 expression was also observed in 3 of 3 surgically resected ADC, 3 of 3 SQC, 2 of 2 SCLC and 1 LCNEC. All 9 carcinomas had cytoplasmic and nuclear PRMT5 expression. Most of the cells within resected tumors showed diffuse cytoplasmic PRMT5 while the number of PRMT5 expressing nuclei varied within a tumor (Figure 2a-c). In addition to diffuse cytoplasmic staining, NSCLC had a distinct nuclear accumulation of PRMT5 forming intranuclear globules (Figure 2b). In contrast, nuclear accumulation of PRMT5 in SCLC was finely granular (Figure 2c). Low level of nuclear PRMT5 was also seen in the alveolar parenchyma adjacent to tumors but not in the parenchyma (Figure 2d) away from tumors (8 of 8 cases).

\section{Cellular localization of PRMT5 correlates with tumor grade (differentiation)}

PRMT5 expression was present in the majority of NSCLC subjected to immunohistochemical analysis (Figure 3a-c). Cytoplasmic PRMT5 was detected in 66.4\% (152 of 229) of cases, including in $20.5 \%$ (47 cases) at high levels. Nuclear PRMT5 was detected in $62.0 \%$ (142 of 229) cases including in $38.0 \%$ (87 cases) at high levels. Correlations between clinicopathological variables and PRMT5 expression in NSCLC are summarized in Table 2. High cytoplasmic PRMT5 was seen in $16.5 \%$ of poorly differentiated NSCLC versus $7.2 \%$ of well and moderately differentiated NSCLC, $\mathrm{p}=0.01$ (Table 2). High cytoplasmic PRMT5 was more common in SQC (12.2\%) than ADC (8.3\%), p =0.04. High cytoplasmic PRMT5 correlated with grade of SQC but not ADC (data not shown). High nuclear PRMT5 was statistically more common in SQC (25.8\%) than in ADC (12.2\%), p $<0.001$. No statistically significant correlation of cellular localization of PRMT5 with patients' age, gender, tumor size, stage (Table 2) or outcome was identified in NSCLC (Tables 2 and 3).

PRMT5 expression was also seen in the majority of pulmonary NET (Figure 3d-e). Cytoplasmic PRMT5 was detected in $88.0 \%$ (117 of 133 cases) of pulmonary NET including at high levels in $16.5 \%$ (22 cases). Nuclear PRMT5 was present in $60.9 \%$ (81 of 133 cases) including at high levels in $24.0 \%$ (32 cases). None of normal

Table 2 PRMT5 expression in NSCLC

\begin{tabular}{|c|c|c|c|c|c|c|}
\hline & & Cytoplasmic high PRMT5, n (\%) & $\mathbf{P}$ & Nuclear high PRMT5, n (\%) & $\mathbf{P}$ & $\mathrm{N}^{\mathrm{a}}$ \\
\hline \multirow[t]{2}{*}{ Age } & $\leq 60$ years $(n=65)$ & $11(5.4)$ & 0.36 & $22(10.8)$ & 0.55 & 204 \\
\hline & $>60$ years $(n=139)$ & $30(14.7)$ & & $55(27.0)$ & & \\
\hline \multirow[t]{2}{*}{ Gender } & Female $(n=53)$ & $9(4.1)$ & 0.79 & $19(8.8)$ & 0.25 & 217 \\
\hline & Male $(n=164)$ & $35(16.1)$ & & $62(28.6)$ & & \\
\hline \multirow[t]{2}{*}{ Size } & $\leq 3 \mathrm{~cm}(\mathrm{n}=74)$ & $9(6.3)$ & 0.09 & $31(21.8)$ & 0.35 & 142 \\
\hline & $>3 \mathrm{~cm}(\mathrm{n}=68)$ & $18(12.7)$ & & $22(15.5)$ & & \\
\hline \multirow[t]{2}{*}{ Stage } & I $(n=81)$ & $14(9.9)$ & 0.63 & $32(22.7)$ & 0.19 & 141 \\
\hline & II-IV $(n=60)$ & $13(9.2)$ & & $21(14.9)$ & & \\
\hline \multirow[t]{2}{*}{ Grade } & $W D, M D(n=55)$ & $7(7.2)$ & 0.01 & $20(20.6)$ & 0.98 & 97 \\
\hline & $\mathrm{PD}(\mathrm{n}=42)$ & $16(16.5)$ & & $16(16.5)$ & & \\
\hline \multirow[t]{2}{*}{ Histology } & $\operatorname{ADC}(n=113)$ & $19(8.3)$ & 0.04 & $28(12.2)$ & $<0.001$ & 229 \\
\hline & $\operatorname{SQC}(n=116)$ & $28(12.2)$ & & $59(25.8)$ & & \\
\hline \multirow[t]{2}{*}{ Survival } & Yes $(n=44)$ & $9(4.8)$ & 0.37 & $14(7.4)$ & 0.54 & 189 \\
\hline & No $(n=145)$ & 30 (15.9) & & $57(30.2)$ & & \\
\hline
\end{tabular}

Abbreviations: Neg negative, $N$ number of cases, WD well differentiated, $M D$ moderately differentiated, $P D$ poorly differentiated, $A D C$ adenocarcinoma, $S Q C$ squamous cell carcinoma.

${ }^{\text {a }}$ Reflects total number of cases with available annotations. 
Table 3 Association of clinicopathological variables with overall survival in univariate and multivariate analyses (p-values; Cox-regression)

\begin{tabular}{|c|c|c|c|c|c|c|c|c|}
\hline & & & & & & ors & & \\
\hline & Uni & Multi & Uni & Multi & Uni & Multi & Uni & Multi \\
\hline PRMT5-Cyto & 0.47 & $\mathrm{NI}$ & 0.99 & $\mathrm{NI}$ & 0.95 & $\mathrm{NI}$ & 0.59 & $\mathrm{NI}$ \\
\hline PRMT5-Nucl & 0.62 & $\mathrm{NI}$ & 0.02 & 0.04 & 0.11 & $\mathrm{NI}$ & 0.98 & $\mathrm{NI}$ \\
\hline Age & 0.84 & $\mathrm{NI}$ & 0.02 & 0.49 & 0.11 & $\mathrm{NI}$ & 0.88 & $\mathrm{NI}$ \\
\hline Gender & 0.01 & 0.03 & 0.33 & $\mathrm{NI}$ & 0.74 & $\mathrm{NI}$ & 0.75 & $\mathrm{NI}$ \\
\hline Size & 0.11 & $\mathrm{NI}$ & 0.71 & $\mathrm{NI}$ & 0.68 & $\mathrm{NI}$ & 0.62 & $\mathrm{NI}$ \\
\hline Grade & 0.79 & $\mathrm{NI}$ & 0.000 & 0.000 & 0.001 & 0.001 & 0.81 & $\mathrm{NI}$ \\
\hline Stage & 0.02 & 0.03 & 0.000 & 0.000 & 0.001 & 0.001 & 0.000 & 0.000 \\
\hline
\end{tabular}

Abbreviations: NET neuroendocrine tumors, HG-NET high grade neuroendocrine tumors, NI not included, NSCLC non-small cell lung carcinoma, Uni univariate analysis, Milti multivariate analysis.

alveolar parenchyma tissue cores showed detectable levels of PRMT5 (0 of 83 cases, Figure 3f). Correlations between clinicopathological variables and PRMT5 expression in NET are summarized in Table 4. Cellular localization of PRMT5 correlated with tumor grade (differentiation), where high cytoplasmic PRMT5 was more frequent in high-grade NET (12.0\%) than in carcinoid tumors (4.5\%), p = 0.04, (Table 4). Conversely, high nuclear PRMT5 was statistically more common in carcinoid tumors (16.5\%) than in high-grade NET (7.5\%), p = 0.02 , (Table 4). No statistically significant correlation of cellular localization of PRMT5 with patients' age, gender, tumor size, or stage was identified in NET. Adjusted for tumor type, no statistically significant correlation of cellular localization of PRMT5 with outcome of pulmonary NET was seen (Tables 4 and 3).

\section{Discussion}

Epigenetic regulation plays an important role in oncogenesis, and histone modification has been recognized as one strategy for modifying epigenetic controls $[25,26]$. It has been shown in cell culture and in animal models that PRMT5 is an important epigenetic modifier of histone and non-histone proteins in lymphomas, breast, colorectal and lung cancer, and its overexpression is associated with aggressive phenotype in these models $[14,17,25,27,28]$. In this study, we further corroborate the previous findings by showing a statistically significant difference in PRMT5 mRNA expression between tumors and matched nonneoplastic lung tissues in surgically resected specimens. We also show that the PRMT5 protein expression is significantly increased in lung cancer but not in nonneoplastic alveolar and bronchial epithelium cell lines. Furthermore, our investigation of a wide spectrum of lung tumors by immunohistochemistry confirms that consistent with quantitative real time PCR results, PRMT5 expression is present in a majority of tumors and its expression supports prior in vitro and in vivo studies suggesting importance of PRMT5 for proliferation of lung cancer cells.

Table 4 PRMT5 expression in NET

\begin{tabular}{|c|c|c|c|c|c|c|}
\hline & & Cytoplasmic high PRMT5, n (\%) & $\mathbf{P}$ & Nuclear high PRMT5, n (\%) & $\mathbf{P}$ & $\mathrm{N}^{\mathrm{a}}$ \\
\hline \multirow[t]{2}{*}{$\overline{\text { Age }}$} & $\leq 60$ years $(n=59)$ & $8(6.3)$ & 0.43 & $12(9.4)$ & 0.61 & 128 \\
\hline & $>60$ years $(n=69)$ & $12(9.4)$ & & $19(14.8)$ & & \\
\hline \multirow[t]{2}{*}{ Gender } & Female $(n=62)$ & $7(5.4)$ & 0.33 & $18(14.0)$ & 0.16 & 129 \\
\hline & Male $(n=67)$ & $14(10.9)$ & & $13(10.1)$ & & \\
\hline \multirow[t]{2}{*}{ Size } & $\leq 3 \mathrm{~cm}(\mathrm{n}=69)$ & $9(8.3)$ & 0.71 & 19 (17.6) & 0.76 & 108 \\
\hline & $>3 \mathrm{~cm}(\mathrm{n}=39)$ & $7(6.5)$ & & $11(10.2)$ & & \\
\hline \multirow[t]{2}{*}{ Stage } & I $(n=69)$ & $12(12.0)$ & 0.48 & $17(17.0)$ & 0.42 & 100 \\
\hline & II-IV $(n=31)$ & $7(7.0)$ & & $10(10.0)$ & & \\
\hline \multirow[t]{2}{*}{ Histology } & Carcinoid $(n=63)$ & $6(4.5)$ & 0.04 & $22(16.5)$ & 0.02 & 133 \\
\hline & HG-NET $(n=70)$ & $16(12.0)$ & & $10(7.5)$ & & \\
\hline \multirow[t]{2}{*}{ Survival } & Yes $(n=46)$ & $8(8.0)$ & 0.923 & $16(16.0)$ & 0.02 & 100 \\
\hline & No $(n=54)$ & $9(9.0)$ & & $8(8.0)$ & & \\
\hline
\end{tabular}


Based on IHC analysis of more than 350 pulmonary tumors, our study also reveals that cytoplasmic PRMT5 is associated with higher grade in both NSCLC and pulmonary NET. Nuclear PRMT5 was more frequent in well-differentiated tumors (carcinoid tumors) than in poorlydifferentiated tumors (SCLC and LCNEC). These findings further support the in vitro observations that cytoplasmic function of PRMT5 relates to silencing of multiple growth promoting and cell death inducing molecular targets $[14,15]$. Similar association was observed in prostate lesions [19]. Based on a subcellular localization assay, it was shown that in prostate cells, the functional activity of PRMT5 depends on its cellular location. In the cytoplasm, PRMT5 was essential for prostate cancer cell growth; in contrast, in the nucleus it inhibited cell growth. Accordingly, PRMT5 was preferentially expressed in nuclei of benign prostate tissues and in cytoplasm of premalignant and malignant lesions [18]. In light of accumulated findings, the differential expression of PRMT5 may speak to the distinct protein targets of this enzyme or to the shuttling of the enzyme in and out of the nucleus. In addition to histones, other intranuclear and cytoplasmic protein targets of PRMT5 have been suggested and demonstrated experimentally [13]. The predilection for cytoplasmic localization of PRMT5 in high-grade tumors may have implications for development of anticancer therapies inhibiting cytoplasmic targets including methylosome [29].

Our study identified that within NSCLC, both cytoplasmic and nuclear PRMT5 expression was more frequent in squamous cell carcinomas than in adenocarcinomas, which is in line with prior observations that DNA methylation is universal phenomenon in lung squamous cell carcinomas $[7,8]$. Cytoplasmic PRMT5 also correlated with grade of NSCLC but not outcome. Only tumor stage and female gender were statistically significant prognostic indicators in the study NSCLC cohort. Nuclear PRMT5 expression was associated with better outcome of all pulmonary NET; however, it was not independent of tumor type and the observed survival benefit was due to predilection of nuclear PRMT5 to carcinoid tumors exhibiting better prognosis.

It has been recognized that genetic instability is common in pulmonary parenchyma adjacent to tumors. Shared genetic changes have been documented in tumors, precursor lesions and non-neoplastic lung parenchyma adjacent to tumors [30]. Chromosome alterations can occur in non-neoplastic bronchial mucosa at a distance of $4 \mathrm{~cm}$ from the tumor boundary [31]. Therefore it is not surprising that in the current study, low levels of PRMT5 expression were noted in reactive tissues adjacent to tumors in resection specimens and not in alveolar parenchyma distant from tumors or normal controls in TMA. Similar to our study, low levels of PRMT5 have been reported at low frequency in normal ovarian tissues and benign ovarian tumors [32]. While PRMT5 overexpression and its cellular localization appear to be associated with more aggressive tumor phenotypes, alterations in PRMT5 expression alone may not necessarily lead to malignant transformation per se, but reflect changes of epigenetic control in oncogenesis. Evaluation of PRMT5 in a broader set of reactive and premalignant pulmonary lesions deserves further investigation.

In summary, our study shows that PRMT5 is significantly overexpressed in neoplastic lung tissues supporting its role in lung tumorigenesis. Cellular localization of PRMT5 correlates with lung tumor grade/differentiation, supporting functional dichotomy of PRMT5 in cellular compartments.

\section{Abbreviations}

PRMT5: Protein arginine methyltransferase-5; HPAEpiC: Human pulmonary alveolar epithelial cells; HBEpiC: Human bronchial epithelial cells; TMA: Tissue microarray; NET: Neuroendocrine tumors; TC: Typical carcinoid; AC: Atypical carcinoid; LCNEC: Large cell neuroendocrine carcinoma; SCLC: Small cell lung carcinoma; ADC: Adenocarcinoma; SQC: Squamous cell carcinoma.

\section{Competing interests}

The authors declare that they have no competing interests.

\section{Authors' contributions}

KS, SS, RB, GAO: conceived and designed the study; XW, SS, WD: performed the experiments; KS, XW, MW, WD: analyzed the data; MV-C, JF, CLH, WZ: contributed reagents/materials/analytic tools; KS, MW, GAO: wrote/edited the paper. All authors read and approved the final manuscript.

\section{Acknowledgements}

The authors are thankful to Susie Johns and Kristin Kovach for help with immunohistochemical studies and Shawn Scully for help with images.

\section{Author details}

${ }^{1}$ Department of Pathology, The Wexner Medical Center at the Ohio State University, 410 W. 10th Avenue, Columbus, OH, 43210, USA. ²Department of Medicine, The Wexner Medical Center at the Ohio State University, Columbus, OH, USA. ${ }^{3}$ Department of Radiology, The Wexner Medical Center at the Ohio State University, Columbus, OH, USA. ${ }^{4}$ Department of Pathology, Nagasaki University School of Medicine, Nagasaki, Japan. ${ }^{5}$ Department of Molecular and Cellular Biochemistry, The Ohio State University, Columbus, $\mathrm{OH}$, USA.

Received: 25 June 2013 Accepted: 3 December 2013

Published: 10 December 2013

\section{References}

1. Siegel R, Naishadham D, Jemal A: Cancer statistics, 2012. CA Cancer J Clin 2012, 62(1):10-29.

2. D'Angelo SP, Pietanza MC, Johnson ML, Riely GJ, Miller VA, Sima CS, Zakowski MF, Rusch WW, Ladanyi M, Kris MG: Incidence of EGFR exon 19 deletions and L858R in tumor specimens from men and cigarette smokers with lung adenocarcinomas. J Clin Oncol 2011, 29(15):2066-2070.

3. Rauch TA, Zhong X, Wu X, Wang M, Kernstine KH, Wang Z, Riggs AD, Pfeifer GP: High-resolution mapping of DNA hypermethylation and hypomethylation in lung cancer. Proc Natl Acad Sci USA 2008, 105(1):252-257.

4. Cancer Genome Atlas Research Network: Comprehensive genomic characterization of squamous cell lung cancers. Nature 2012, 489(7417):519-525.

5. Vaitkiene P, Skiriute D, Skauminas K, Tamasauskas A: GATA4 and DcR1 methylation in glioblastomas. Diagn Pathol 2013, 8:7.

6. Guzman L, Depix MS, Salinas AM, Roldan R, Aguayo F, Silva A, Vinet R: Analysis of aberrant methylation on promoter sequences of tumor suppressor genes and total DNA in sputum samples: a promising tool 
for early detection of COPD and lung cancer in smokers. Diagn Pathol 2012, 7:87

7. Toyooka S, Toyooka KO, Maruyama R, Virmani AK, Girard L, Miyajima K, Harada K, Ariyoshi Y, Takahashi T, Sugio K, et al: DNA methylation profiles of lung tumors. Mol Cancer Ther 2001, 1(1):61-67.

8. Ji M, Zhang Y, Shi B, Hou P: Association of promoter methylation with histologic type and pleural indentation in non-small cell lung cancer (NSCLC). Diagn Pathol 2011, 6:48.

9. Herman JG, Merlo A, Mao L, Lapidus RG, Issa JP, Davidson NE, Sidransky D, Baylin SB: Inactivation of the CDKN2/p16/MTS1 gene is frequently associated with aberrant DNA methylation in all common human cancers. Cancer Res 1995, 55(20):4525-4530.

10. Otterson GA, Khleif SN, Chen W, Coxon AB, Kaye FJ: CDKN2 gene silencing in lung cancer by DNA hypermethylation and kinetics of p16INK4 protein induction by 5-aza 2'deoxycytidine. Oncogene 1995, 11(6):1211-1216

11. Wijermans P, Lubbert M, Verhoef G, Bosly A, Ravoet C, Andre M, Ferrant A: Low-dose 5-aza-2'-deoxycytidine, a DNA hypomethylating agent, for the treatment of high-risk myelodysplastic syndrome: a multicenter phase II study in elderly patients. J Clin Oncol 2000, 18(5):956-962.

12. Silverman LR, Demakos EP, Peterson BL, Kornblith AB, Holland JC, OdchimarReissig R, Stone RM, Nelson D, Powell BL, DeCastro CM, et al: Randomized controlled trial of azacitidine in patients with the myelodysplastic syndrome: a study of the cancer and leukemia group B. J Clin Oncol 2002, 20(10):2429-2440.

13. Bedford MT, Richard S: Arginine methylation an emerging regulator of protein function. Mol Cell 2005, 18(3):263-272

14. Pal S, Sif S: Interplay between chromatin remodelers and protein arginine methyltransferases. J Cell Physiol 2007, 213(2):306-315.

15. Pal S, Vishwanath SN, Erdjument-Bromage H, Tempst P, Sif S: Human SWI/ SNF-associated PRMT5 methylates histone $\mathrm{H} 3$ arginine 8 and negatively regulates expression of ST7 and NM23 tumor suppressor genes. Mol Cell Biol 2004, 24(21):9630-9645

16. Wang L, Pal S, Sif S: Protein arginine methyltransferase 5 suppresses the transcription of the RB family of tumor suppressors in leukemia and lymphoma cells. Mol Cell Biol 2008, 28(20):6262-6277.

17. Gu Z, Gao S, Zhang F, Wang Z, Ma W, Davis RE: Protein arginine methyltransferase 5 is essential for growth of lung cancer cells. Biochem J 2012, 446(2):235-241.

18. Gu Z, Li Y, Lee P, Liu T, Wan C, Wang Z: Protein arginine methyltransferase 5 functions in opposite ways in the cytoplasm and nucleus of prostate cancer cells. PLOS One 2012, 7(8):e44033.

19. Karkhanis $V$, Wang L, Tae S, Hu YJ, Imbalzano AN, Sif S: Protein arginine methyltransferase 7 regulates cellular response to DNA damage by methylating promoter histones $\mathrm{H} 2 \mathrm{~A}$ and $\mathrm{H} 4$ of the polymerase delta catalytic subunit gene, POLD1. J Biol Chem 2012, 287(35):29801-29814.

20. Friesen WJ, Paushkin S, Wyce A, Massenet S, Pesiridis GS, Van Duyne G, Rappsilber J, Mann M, Dreyfuss G: The methylosome, a 20S complex containing JBP1 and plCln, produces dimethylarginine-modified Sm proteins. Mol Cell Biol 2001, 21(24):8289-8300.

21. Friesen WJ, Wyce A, Paushkin S, Abel L, Rappsilber J, Mann M, Dreyfuss G: A novel WD repeat protein component of the methylosome binds Sm proteins. J Biol Chem 2002, 277(10):8243-8247.

22. Antonysamy S, Bonday Z, Campbell RM, Doyle B, Druzina Z, Gheyi T, Han B, Jungheim LN, Qian Y, Rauch C, et al: Crystal structure of the human PRMT5:MEP50 complex. Proc Natl Acad Sci USA 2012, 109(44):17960-17965.

23. Fukuoka J, Dracheva T, Shih JH, Hewitt SM, Fujii T, Kishor A, Mann F, Shilo K, Franks TJ, Travis WD, et al: Desmoglein 3 as a prognostic factor in lung cancer. Hum Pathol 2007, 38(2):276-283.

24. Shilo K, Dracheva T, Mani H, Fukuoka J, Sesterhenn IA, Chu WS, Shih JH, Jen J, Travis WD, Franks TJ: Alpha-methylacyl CoA racemase in pulmonary adenocarcinoma, squamous cell carcinoma, and neuroendocrine tumors: expression and survival analysis. Arch Pathol Lab Med 2007, 131(10):1555-1560

25. Espino PS, Drobic B, Dunn KL, Davie JR: Histone modifications as a platform for cancer therapy. J Cell Biochem 2005, 94(6):1088-1102.

26. Van Den Broeck A, Ozenne P, Eymin B, Gazzeri S: Lung cancer: a modified epigenome. Cell Adh Migr 2010, 4(1):107-113.

27. Powers MA, Fay MM, Factor RE, Welm AL, Ullman KS: Protein arginine methyltransferase 5 accelerates tumor growth by arginine methylation of the tumor suppressor programmed cell death 4. Cancer Res 2011, 71(16):5579-5587.

28. Cho EC, Zheng S, Munro S, Liu G, Carr SM, Moehlenbrink J, Lu YC, Stimson L, Khan $\mathrm{O}$, Konietzny $\mathrm{R}$, et al: Arginine methylation controls growth regulation by E2F-1. Embo J 2012, 31(7):1785-1797.

29. Lu Q, Li N, Luo J, Yu M, Huang Y, Wu X, Wu H, Liu XY, Li G: Pinellia pedatisecta agglutinin interacts with the methylosome and induces cancer cell death. Oncogenesis 2012, 1:e29.

30. Gradowski JF, Mantha GS, Hunt JL, Dacic S: Molecular alterations in atypical adenomatous hyperplasia occurring in benign and cancer-bearing lungs. Diagn Mol Pathol 2007, 16(2):87-90.

31. Kayser K, Kosjerina Z, Goldmann T, Kayser G, Kazmierczak B, Vollmer E: Lung carcinoma-associated atypical adenomatoid hyperplasia, squamous cell dysplasia, and chromosome alterations in non-neoplastic bronchial mucosa. Lung Cancer 2005, 47(2):205-214

32. Bao X, Zhao S, Liu T, Liu Y, Yang X: Overexpression PRMT5 promotes tumor cell growth and is associated with poor disease prognosis in epithelial ovarian cancer. J Histochem Cytochem 2013, 61(3):206-217.

doi:10.1186/1746-1596-8-201

Cite this article as: Shilo et al:: Cellular localization of protein arginine methyltransferase- 5 correlates with grade of lung tumors. Diagnostic Pathology 2013 8:201.

\section{Submit your next manuscript to BioMed Central and take full advantage of:}

- Convenient online submission

- Thorough peer review

- No space constraints or color figure charges

- Immediate publication on acceptance

- Inclusion in PubMed, CAS, Scopus and Google Scholar

- Research which is freely available for redistribution 